\title{
Synthesis and Characterization of Cowry and Crab Shells Based Chitosan for Drug Delivery
}

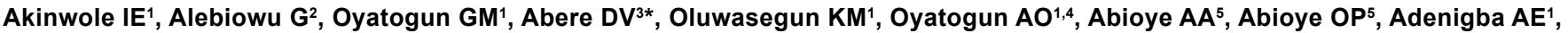 \\ Ayodele TJ1 \\ ${ }^{1}$ Department of Materials Science and Engineering, Obafemi Awolowo University, Ile-lfe, Nigeria \\ ${ }^{2}$ Department of Pharmaceutics, Faculty of Pharmacy, Obafemi Awolowo University, Ile-Ife, Nigeria \\ ${ }^{3}$ Department of Metal Processing and Production, National Metallurgical Development Centre, Jos, Nigeria \\ ${ }^{4}$ Department of Chemical Metallurgical and Materials Engineering, Faculty of Engineering and the Built Environment, Tshwane University of Technology, Pretoria, South Africa \\ ${ }^{5}$ Department of Mechanical Engineering, Covenant University, Ota, Nigeria
}

\begin{abstract}
This work aims to synthesize chitosan from locally available cowry and crab shells for Pharmaceutical application in drug delivery. Chitosan was synthesized from both shells using standard deacetylation technique. The synthesized chitosan, piroxicam and lactose were employed in preparing the drug loaded tablets by direct compression technique and subjected to characterization with the aid of Fourier Transform Infrared Spectroscopy (FTIR), Scanning Electron Spectroscopy (SEM) and optical microscopy. Finally, the drug release rate was investigated with in vitro drug dissolution test. The results of FTIR spectra confirmed that the biopolymer extract was chitosan and it also shows that there was no interaction between chitosan and the piroxicam. The morphological properties of the samples were found to be suitable for drug delivery. The applied load and composition of tablets influenced the drug release rates.
\end{abstract}

Keywords: Piroxicam; Cowry shell; Drug delivery; Crab shell; Chitosan

\section{Introduction}

The National Institutes of Health Consensus Development Conference defined a biomaterial as "any substance (other than a drug) or combination of substances, synthetic or natural in origin, which can be used for any period of time, as a whole or as a part of a system which treats, augments, or replaces any tissue, organ, or function of the body" (10) while Williams defined a biomaterial as a nonviable material used in a medical device, intended to interact with biological systems (36). Some of the main areas of applications of biomaterials are classified into:

- Cardiovascular medical devices (stents, grafts and etc.)

- Orthopedic and dental applications (implants, tissue engineered scaffolds and etc.)

- Ophthalmologic applications (contact lenses, retinal prostheses and etc.)

- Bio-electrodes and biosensors.

- Burn dressings and skin substitutes.

- Sutures.

- Drug delivery systems.

However, this work focuses on the application of biomaterial in drug delivery systems $(D D S)$. Drug delivery systems introduced as formulations or instruments which enable to control the release rate of a biological agent (most especially a drug) in the target site. Drug delivery systems are an interface between patient and drug. Drugs can be introduced to the organ by various anatomical routes due to disease and drug type: Digestive system (oral, anal), oral, rectal, parenteral (subcutaneous, intramuscular, intravenous, arterial), mucous membranes, respiratory tract by inhalation, subcutaneous or intraosseous are man anatomical routes [1-12]. The various classifications of controlled released systems are indicated in Table 1 [13-24].

Piroxicam is a non-steroidal anti-inflammatory drug (NSAID) used in treatment of different types of arthritis such as osteoarthritis,

\begin{tabular}{|c|c|}
\hline Type of system & Rate-control mechanism \\
\hline $\begin{array}{c}\text { Diffusion control reservoir } \\
\text { devices }\end{array}$ & Diffusion through membrane \\
\hline $\begin{array}{c}\text { Monolithic devices } \\
\text { Water penetration } \\
\text { controlled osmotic systems }\end{array}$ & $\begin{array}{c}\text { Osmotic transport of water through semi permeable } \\
\text { membrane }\end{array}$ \\
\hline $\begin{array}{c}\text { Swelling systems } \\
\text { Chemically controlled } \\
\text { monolithic systems }\end{array}$ & $\begin{array}{c}\text { Either pure polymer erosion (surface erosion) or } \\
\text { combination of erosion and diffusion (bulk erosion }\end{array}$ \\
\hline $\begin{array}{c}\text { Pendant chain systems } \\
\text { Combination of hydrolysis of pendant group and } \\
\text { diffusion from bulk polymer }\end{array}$ \\
\hline $\begin{array}{c}\text { Regulated systems } \\
\text { magnetic or ultrasound }\end{array}$ & $\begin{array}{c}\text { External application of magnetic field or ultrasound } \\
\text { to device. }\end{array}$ \\
\hline Chemical & $\begin{array}{c}\text { Use of competitive desorption or enzyme-substrate } \\
\text { reactions. Rate control is built into device. }\end{array}$ \\
\hline
\end{tabular}

Table 1: Classifications of controlled released systems.

rheumatoid arthritis, ankylosing spondylitis and acute gout disease [14]. It has a plasma half-life of approximately $50 \mathrm{hrs}$ [25-30]. The chemical name for piroxicam is 4-hydroxy-2-methyl-N-2-pyridinyl$2 \mathrm{H}-1,2$ benzothiazine-3-carboxamide 1,1-dioxide. It is a member of the oxicam family, which though not carboxylic acids, are acidic by virtue of the enolic 4-hydroxy substituent (Figure 1). Piroxicam has poor solubility in water and when administered orally remains un-dissolve in the acidic environment such as obtained in the stomach causing bioavailability problems which may consequently lead to delay in the

*Corresponding author: Dare Victor Abere, Department of Metal Processing and Production, National Metallurgical Development Centre, Jos, Nigeria, Tel: +234 1 270 5612; E-mail: aberevictor@gmail.com

Received January 29, 2018; Accepted February 10, 2018; Published February 16, 2018

Citation: Akinwole IE, Oyatogun GM, Adenigba AE, Ayodele TJ, Oluwasegun KM, et al. (2018) Synthesis and Characterization of Cowry and Crab Shells Based Chitosan for Drug Delivery. Bioceram Dev Appl 8: 107. doi: 10.4172/20905025.1000107

Copyright: (c) 2018 Akinwole IE, et al. This is an open-access article distributed under the terms of the Creative Commons Attribution License, which permits unrestricted use, distribution, and reproduction in any medium, provided the original author and source are credited. 
onset of drug effect [31-34]. In order to overcome these problems, it becomes necessary to develop a drug delivery system that will improve the solubility of piroxicam in the stomach.

Polymers are extensively used for the drug delivery. It has been established that they have the ability to form a matrix, or a membrane, that can control the release of drugs over a prolonged period, thus avoiding repetitive dosing. They have also been used to form (nano) carriers to deliver drugs with low solubility or biotechnology-based drugs $[23,25]$. Biodegradable polymers have found wide applications in drug delivery due to the ease of removal of the carrier after the release of the active pharmaceutical ingredients. To avoid side effects, especially when the carrier is injected, the polymer must be biocompatible. On this basis, natural polymers such as polysaccharides, polypeptides, or phospholipids are generally used as building blocks for drug formulations [8,20,31,35-38].

Chitosan is a nontoxic, biodegradable and biocompatible linear polysaccharide composed of randomly distributed $\beta$ - $(1 \rightarrow 4)$-linked D-glucosamine (Figure 2) that has found diverse applications in drug delivery $[23,27,28,32,33]$. Over the last few decades, investigations had been focused on applications of chitosan and its fabricated products in drug delivery $[2,13,35]$.

This study is therefore aimed at utilization of chitosan that will be synthesized from locally sourced crab and cowry shells, as a drug delivery vehicle that will enhance the bioavailability of piroxicam while simultaneously facilitating the controlled release of the drug $[11,29]$.

\section{Materials and Methods}

\section{Materials}

The materials used were cowry shells and crab shells (sourced from Bode market, Challenge, Ibadan, South Western Nigeria), hydrochloric acid, sodium hydroxide, (BDH Chemicals Ltd Poole, England), acetone (Sigma-Aldrich Laborchemickalien GMBH, Seelze, Germany), piroxicam (Bond Chemicals, Awe, Nigeria), lactose, magnesium stearate, talc (Merck KGaA, Darmstadt, Germany) and di-potassium hydrogen orthophosphate (BDH Chemicals Ltd Poole, England).

\section{Methods}

The work entails the extraction of chitosan from cowry and crab shells, formulation of drug, and characterization of the synthesized chitosan and formulated tablet. This was with a view to ascertaining the suitability of the chitosan obtained from both shells for controlled drug delivery.

Chitosan synthesis: The cowry and crab shells were thoroughly

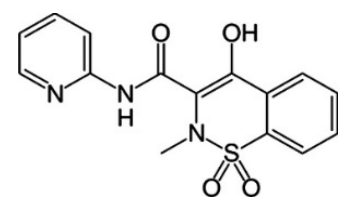

Figure 1: Structure of piroxicam.

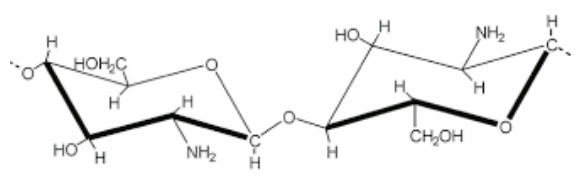

Figure 2: Structure of chitosan washed to remove impurities such as sand, dirt and insect larva and subsequently oven-dried at $60^{\circ} \mathrm{C}$. The washed and dried shells were then pulverized using a Rocklabs mill to pass through a $250 \mu \mathrm{m}$ sieve. Deproteinization of the shell was carried out by weighing eighty grams of the pulverized shells into a conical flask and adding $0.1 \mathrm{M}$ sodium hydroxide to it. The mixture was boiled and stirred at $100^{\circ} \mathrm{C}$ for $2 \mathrm{~h}$ in a water bath to remove the protein. The product was decolorized by soaking in pure acetone for $24 \mathrm{~h}$. It was then sieved with $300 \mu \mathrm{m}$ sieve, washed to neutrality and dried in the oven at $100^{\circ} \mathrm{C}$ for $2 \mathrm{~h}$. This was followed by demineralization using $0.5 \mathrm{M}$ hydrochloric acid to eliminate the calcium carbonate.

The residue, chitin, was scrapped into a Petri dish and dried in the oven at $100^{\circ} \mathrm{C}$ for $2 \mathrm{~h}$. The chitin was then deacetylated by boiling in $0.2 \mathrm{M}$ sodium hydroxide, at $100^{\circ} \mathrm{C}$ for $2 \mathrm{~h}$ to produce the chitosan. This was washed and tested with litmus paper to ensure a complete removal of the sodium hydroxide. Finally, the chitosan was oven dried at $90^{\circ} \mathrm{C}$ for $24 \mathrm{~h}$.

Preparation of piroxicam powder formulation: A $100 \mathrm{~g}$ batch of chitosan /piroxicam powder formulation was prepared using the different percentage compositions given in Table 1. Where piroxicam, the active drug ingredient, designated as $\mathrm{P}$, was maintained at a constant dosage of $10 \mathrm{mg}$ while the excipient, composed of the lactose (designated as $\mathrm{L}$, which served as the filler) and the chitosan (designated as CCR and CCW for chitosan extracted from crab shell and cowry shell respectively) were varied in order to study the effects of their increasing weight percent on the physical, mechanical and dissolution properties of the formulated drug.

Each batch of $200 \mathrm{mg} \pm 2 \mathrm{mg}$ piroxicam formulated powder was compressed for 30 seconds into tablets with predetermined loads ranging from 69.36 to $208.08 \mathrm{MPa}$ on a Carver hydraulic press (Model C, Carver Inc. Wisconsin, USA), using an eight $\mathrm{mm}$ die and flat faced punch. The dies and punches were lubricated with a $2 \% \mathrm{w} / \mathrm{v}$ dispersion of magnesium stearate and talc in acetone prior to each compression [4]. After ejection, the tablets were stored over silica gel for $24 \mathrm{~h}$ to allow for elastic recovery and prevent false low yield values [3].

Fourier Transform Infrared (FTIR) Spectroscopy: The FTIR spectra of chitosan obtained from crab and cowry shell (CCR and CCW) were recorded using an infrared spectrophotometer (Model IR Prestige 21, Shimadzu). All the Infrared spectra were recorded at resolution of 4 $\mathrm{cm}^{-1}$ over the frequency range from $4000-400 \mathrm{~cm}^{-1}$. Similarly the FTIR spectrum of the piroxicam loaded chitosan was studied to evaluate the interaction of the drug with the chitosan.

Analysis of particle shape and size: The morphology of the synthesized chitosan was studied using the scanning electron microscopy technique. Particle shape and size of samples from the synthesized materials and formulated drug were determined using optical microscopy. Optical images of the synthesized material were captured using an optical microscope (Leica Galen III Compound microscope with celestron digital microscope camera). The images were then analyzed using Image Pro Premier software (Media Cybernetics, Bethesda, MD, USA) in order to determine the particle descriptors of major and minor axis, length, perimeter and projected area. The shape factors, aspect ratio, roundness, irregularity and equivalent diameter were determined using equations (1-4).

$$
\begin{aligned}
& \text { Aspect Ratio }=\frac{b}{l} \\
& \text { Irregularity }=\frac{p}{l}
\end{aligned}
$$




$$
\text { Irregularity }=\frac{p}{l}
$$

$$
\text { Equivalent Circle Diameter }(E C D)=2 * \sqrt{\frac{A}{x}}
$$

(Where; $\mathrm{b}=$ Length of the minor axis, minimum Feret diameter, $\mathrm{l}=$ Length of the major diameter, maximum Feret diameter, $\mathrm{A}=$ Projected area of the particle and $\mathrm{P}=$ Perimeter)

Dissolution test for piroxicam tablet formulation: The dissolution rate of the piroxicam tablet was determined at $37 \pm 0.5^{\circ} \mathrm{C}$ in $750 \mathrm{ml}$ of $0.1 \mathrm{M}$ hydrochloric acid using a Veego dissolution testing station and a stirring speed of 100 revolutions per minute. The tablet was placed in the rotating basket and $5 \mathrm{ml}$ of the medium was sampled with a pipette after every 30 minutes. The same quantity of the medium was added at the same temperature immediately after each sampling to keep the volume of the dissolution medium constant. After $2 \mathrm{~h}$ of testing in $0.1 \mathrm{M}$ of hydrochloric acid, the operation was completed by adding buffer and adjusting the $\mathrm{pH}$ within 5 minutes. With the apparatus in operation, 250 $\mathrm{ml}$ of $0.20 \mathrm{M}$ solution of $d i$-potassium hydrogen orthophosphate that has been equilibrated to $37 \pm 0.5^{\circ} \mathrm{C}$ was added and it was adjusted with $31 \mathrm{ml}$ of $2.0 \mathrm{M}$ of sodium hydroxide to a $\mathrm{pH}$ of $6.8 \pm 0.05$. The operation was continued for $4 \mathrm{~h}$. The concentration of dissolved piroxicam in the medium was determined spectrophotometrically using a Unicam 8620 $\mathrm{UV} /$ visible spectrophotometer (Pye Unicam, UK) at a wavelength of $360 \mathrm{~nm}$. All determinations were made in triplicate and the results were given as average values.

\section{Results and Discussion}

\section{Fourier Transform Infrared (FTIR) Spectroscopy}

The FTIR spectra for biopolymer extracts and the formulated piroxicam powder are presented in Figure 3. These spectra confirmed that the structures of the two different chitosan are indeed chitosan. (6, 21) It is reported that the FTIR spectrum of chitosan exhibits major bands at $3444 \mathrm{~cm}^{-1}, 2919 \mathrm{~cm}^{-1}, 1659 \mathrm{~cm}^{-1}, 1420 \mathrm{~cm}^{-1}, 1080 \mathrm{~cm}^{-1}$ and $1033 \mathrm{~cm}^{-1}$ corresponding to $\mathrm{OH}$ group $\left(3444 \mathrm{~cm}^{-1}\right)$, stretching of $\mathrm{CH}_{2}$ $\left(2919 \mathrm{~cm}^{-1}\right)$, amide I band $\left(1659 \mathrm{~cm}^{-1}\right)$, vibration of $\mathrm{OH}$ ring $(1420 \mathrm{~cm}$ $\left.{ }^{1}\right)$, stretching of $\mathrm{CH}\left(1080 \mathrm{~cm}^{-1}\right)$ and $-\mathrm{C}-\mathrm{O}-\mathrm{C}$ linkage $\left(1033 \mathrm{~cm}^{-1}\right)$. These bands, which are the main characteristic bands of chitosan $[18,24]$, are similar to those observed in the spectrum of the chitosan synthesized from the crab and cowry shells, CCR and CCW (Figure 3), i.e., 3448.84 $\mathrm{cm}^{-1}, 2931.90 \mathrm{~cm}^{-1}, 1654.98 \mathrm{~cm}^{-1}, 1429.3 \mathrm{~cm}^{-1}, 1070.53 \mathrm{~cm}^{-1}$ and 1033.88 $\mathrm{cm}^{-1}$ Similarly, NH stretching bands are found in the spectrum of CCR and CCW at $3109.35 \mathrm{~cm}^{-1}$ and $3232.08 \mathrm{~cm}^{-1}$ which is similar to what was observed by Mohammed et al. [17]. Consequently, it can be stated that the biopolymer extracts from crab and cowry shell are chitosan.

In addition, the absorption bands used to distinguish protein $\left(1540 \mathrm{~cm}^{-1}\right)$ and mineral $\left(1798\right.$ and $\left.876 \mathrm{~cm}^{-1}\right)$ were not observed in the spectrum. The absence of both protein and mineral matters indicate that the materials may not elicit any cyto-toxic or adverse immunological response in the host when administered.

Furthermore, the spectrum of P-CCR and P-CCW, Figure 3b, displays absorption bands at $3448.84 \mathrm{~cm}^{-1}, 3338.89 \mathrm{~cm}^{-1}, 3103.57 \mathrm{~cm}^{-1}$, $2931.90 \mathrm{~cm}^{-1}, 2521.05 \mathrm{~cm}^{-1}, 1629.90 \mathrm{~cm}^{-1}, 1577.82 \mathrm{~cm}^{-1}, 1529.60 \mathrm{~cm}$ ${ }^{1}, 1435.09 \mathrm{~cm}^{-1}, 1352.14 \mathrm{~cm}^{-1}, 1300.07 \mathrm{~cm}^{-1}, 1215.19 \mathrm{~cm}^{-1}, 1182.40 \mathrm{~cm}^{-}$ ${ }^{1}, 1149.61 \mathrm{~cm}^{-1}, 1120.68 \mathrm{~cm}^{-1}, 1039.67 \mathrm{~cm}^{-1}, 991.44 \mathrm{~cm}^{-1}, 939.36 \mathrm{~cm}^{-1}$, $875.71 \mathrm{~cm}^{-1}, 831.35 \mathrm{~cm}^{-1}, 773.48 \mathrm{~cm}^{-1}, 732.97 \mathrm{~cm}^{-1}, 690.54 \mathrm{~cm}^{-1}, 619.17$ $\mathrm{cm}^{-1}, 565.16 \mathrm{~cm}^{-1}, 526.58 \mathrm{~cm}^{-1}$ and $457.14 \mathrm{~cm}^{-1}$ It can be observed that the bands of chitosan were separated from that of piroxicam showing

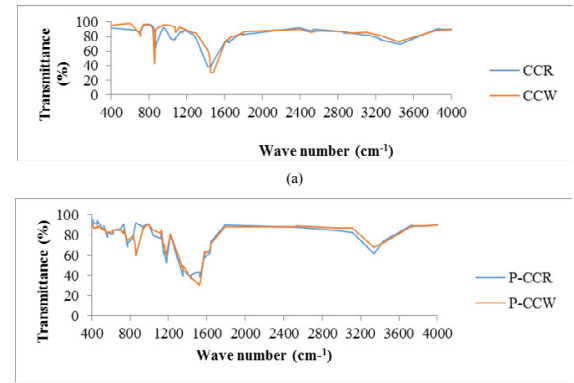

(b)

Figure 3: FTIR spectrum for (a) chitosan and (b) the formulated piroxicam/ chitosan powder.

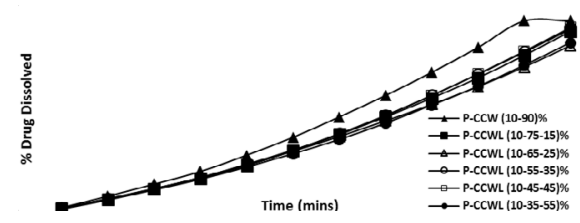

Figure 4: Plots of \% drug released with time (min) for piroxicam tablets compressed at $104.04(\mathrm{MPa})$.

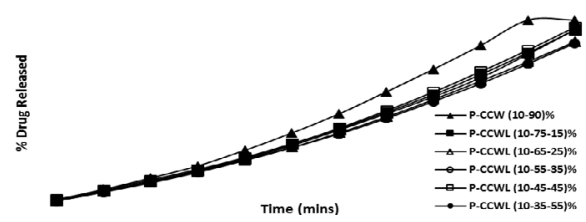

Figure 5: Plots of \% drug released against time (mins) for piroxicam tablets compressed at $138.72(\mathrm{MPa})$

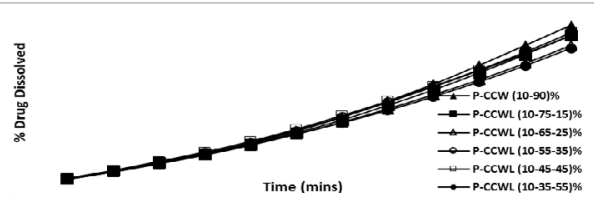

Figure 6: Plots of \% drug released against time ( $\mathrm{min})$ for piroxicam tablets compressed at $173.40(\mathrm{MPa})$.

that there is no interaction between the chitosan obtained from crab shell (CCR) and the active pharmaceutical ingredient, piroxicam. A similar trend was observed in the spectrum of P-CCW, which displays absorption bands at $3853.90 \mathrm{~cm}^{-1}, 3736.24 \mathrm{~cm}^{-1}, 3446.91 \mathrm{~cm}^{-1}, 3338.89$ $\mathrm{cm}^{-1}, 2931.90 \mathrm{~cm}^{-1}, 2521.05 \mathrm{~cm}^{-1}, 1791.93 \mathrm{~cm}^{-1}, 1629.90 \mathrm{~cm}^{-1}, 1525.74$ $\mathrm{cm}^{-1}, 1479.45 \mathrm{~cm}^{-1}, 1435.09 \mathrm{~cm}^{-1}, 1352.14 \mathrm{~cm}^{-1}, 1300.07 \mathrm{~cm}^{-1}, 1215.19$ $\mathrm{cm}^{-1}, 1182.40 \mathrm{~cm}^{-1}, 1149.61 \mathrm{~cm}^{-1}, 1039.67 \mathrm{~cm}^{-1}, 939.36 \mathrm{~cm}^{-1}, 860.28$ $\mathrm{cm}^{-1}, 831.35 \mathrm{~cm}^{-1}, 773.48 \mathrm{~cm}^{-1}, 732.97 \mathrm{~cm}^{-1}, 626.89 \mathrm{~cm}^{-1}, 565.16 \mathrm{~cm}^{-1}$, $526.58 \mathrm{~cm}^{-1}, 457.14 \mathrm{~cm}^{-1}$ and $418.57 \mathrm{~cm}^{-1}$ indicating that there was no interaction between chitosan obtained from cowry shell (CCW) and piroxicam.

\section{Dissolution properties of piroxicam tablets}

The dissolution results, presented in the form of percentage drug released with time, are shown in Figures 4-6. Generally, polymer dissolution and erosion take place in three steps: Solvent penetration into the polymer matrix, polymer chain disentanglement and attainment of the threshold disentanglement. When solvent penetrates into the polymer matrix, it enhances the mobility of the polymer chains which eventually disentangle at the advancing front, separating the 


\begin{tabular}{|c|c|c|c|c|c|}
\hline \multirow{2}{*}{ Ingredients (\%) } & \multicolumn{4}{|c|}{ Formulation } \\
\cline { 2 - 5 } & $\begin{array}{c}\text { P-CCR/ P-CCW } \\
\text { (10-90) }\end{array}$ & $\begin{array}{c}\text { P-CCRL/P-CCWL (10- } \\
\text { P-CCRL/P-CCWL (10- }\end{array}$ & $\begin{array}{c}\text { P-CCRL/P-CCWL (10- } \\
\text { 55-35) }\end{array}$ & $\begin{array}{c}\text { P-CCRL/-CCWL (10- } \\
\text { 45-45) }\end{array}$ & $\begin{array}{c}\text { P-CCRL/P-CCWL (10- } \\
\text { 35-55) }\end{array}$ \\
\hline Piroxicam (P \%) & 10 & 10 & 10 & 10 \\
\hline (CCR/CCW \%) & 90 & 75 & 65 & 55 \\
\hline Lactose (L\%) & - & 15 & 25 & 35 \\
\hline
\end{tabular}

Table 2: Chitosan piroxicam powder formulation.

bond layer from the erosion/dissolution front. Chitosan disentangles as solvent passes through the pores, which provided an avenue for the drug release rate to increase. Thus, the synthesized chitosan was found to be an effective rate controlling polymer; by increasing the amount of chitosan $(\mathrm{CCR} / \mathrm{CCW})$ the drug release rate was observed to increase for the different formulations that were compressed using different compacting pressure as shown in Figures 4-6.

Effect of changes in compacting pressure and time on the drug released rate for the formulated tablets can be observed in Figures 4-6. Increase in the amount of drug released was observed with increasing time for all the formulation. However, the applied compacting pressure was also found to have influenced the drug release rate. The time taken for $50 \%$ of drug to be released for formulations manufactured using different compression forces indicated that drug release become slower with increasing applied force. This effect is particularly notice when comparing tablets manufactured using a very low compression force of $104.04 \mathrm{MPa}$ with the tablets manufactured at higher compression forces of $138.72 \mathrm{MPa}$ and $173.40 \mathrm{MPa}$. Depending on the compressibility behavior of the piroxicam powder, the porosity of the matrices was reduced with increasing compression force. This resulted in slower media uptake and media front movement into the matrix and consequently slow drug release rate.

Furthermore, the observed drug release rate was found to be higher in the formulations that had no lactose, the (10-90\%) P-CCW and P-CCR formulation, compressed using different compressive forces. It can be noted that the piroxicam in the tablets were released before 6 hours. This may be due to the absence of lactose which serves as filler in the drug matrix. Lactose in the matrix results in lower porosity of the compacted tablet, hence lower drug release rate. Increasing concentration of lactose however resulted in improved osmotic pressure that may lead to accelerated water penetration into the matrix, resulting in a higher degree of polymer swelling and formation of more microcavities [22]. Lactose, being water-soluble, produces more pores when in contact with water, forming more micro-cavities during the various mesophase formations. This causes the osmotic effect which promotes the erosion of chitosan [26] and subsequently the observed increase in the drug released from the matrices with increasing concentration of lactose. The lactose was therefore found to shortens the penetration time of the dissolution medium into the matrix and to also acts as a channeling agent by rapidly dissolving and easily diffusing outward, therefore increasing the matrix porosity with time. Consequently, the lactose was found to enhance the achievement of predetermined drug release profiles in the chitosan based controlled release matrices.

\section{Microscopic and morphological properties of the samples}

Optical microscopic imaging and quantitative image analyses have advanced the morphological characterization of powders, and the subsequent ability to use the knowledge acquired from such exercise to make important decisions during powder handling and the formulation of pharmaceutical dosage forms. Various morphological descriptors have been proposed and used by different image analysis software $[1,5,7]$. The results of the shape descriptors study carried out on the
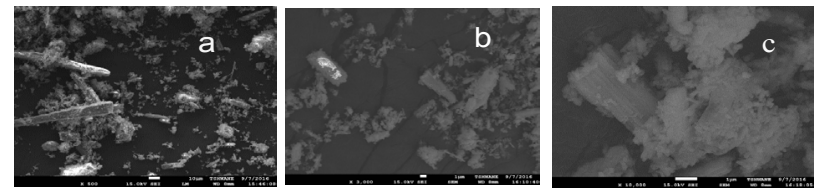

Figure 7: SEM micrographs of chitosan at magnifications of (a) 500 (b) 3,000 and (c) 10,000

powdered samples of the synthesized materials, which include the aspect ratio, elongation, roundness, irregularity and equivalent circle diameter are presented in Table 2. From the result, it can be observed that all the samples have roundness value less than one. Roundness is a measure of how closely the projected area of the particle resembles a circle; with a perfect circle having a roundness value of 1 . The higher the roundness value, the higher the percentage porosity, the better the flow rate. The CCR and CCW have higher roundness values $(0.82$ and 0.85 respectively) when compared to what was obtained for the different drug formulations. Consequently, they are less densely packed and have higher porosity. Correspondingly, P-CCW and P- CCR (10-90\%) has the highest roundness value of 0.64 and 0.68 respectively in the drug formulation. Thus, they have higher porosity and higher rate of release of the active drug ingredient (Figures 4-6).

Aspect ratio takes into consideration the maximum and minimum Feret's diameter and these are utilized in the calculation of length and breadth of the particle $(5,1)$. It may be noted that the P-CCRL (10-35$55 \%)$ has the lowest aspect ratio of 0.19 . This may be responsible for its good packing properties, low percentage porosity and subsequently the observed low delivery of piroxicam, when compared to the other formulation. Similarly, irregularity measures the surface area compared to the size of the particle. A perfect circle, for example, has an irregularity of $\pi[1,15,37,38]$. In the powder formulation, it can be observed that P-CCW (10-90\%) has the highest irregularity value of 2.94 while P-CCRL (10-35-55\%) has the lowest is 2.29 . These results further support the result of the aspect ratio and also the results obtained from SEM analysis (Figure 7) and proved that the powders were far from being perfect circles. These parameters may be responsible for the formulation having only CCR and CCW; which has the highest roundness value, highest irregularity and aspect ratio, hence closest to having circular configuration of all the samples. This resulted in it being less densely packed, consequently its high porosity, which led to the observed high drug release rate (Figures 4-6). In the same vein, it may be noted that P-CCRL (10-35-55\%) that has the lowest aspect ratio of 2.29 is more densely packed, hence it has low porosity and consequently low drug release rate.

The particle size of the samples was determined using the equivalent circle diameter (ECD), which measures the diameter of a circle having the same cross sectional area as the powder. The higher is the ECD, the larger the mean particle size [9]. Particle size had also been reported to affect the flow and packing properties of powder systems and their behavior during procedures involving bulk powder handling $[16,19]$. From Table 3, the extracted biopolymer, CCR and CCW, have lowest particle size, 9.07 and 9.00 respectively, this may be responsible for 
Citation: Akinwole IE, Oyatogun GM, Adenigba AE, Ayodele TJ, Oluwasegun KM, et al. (2018) Synthesis and Characterization of Cowry and Crab Shells Based Chitosan for Drug Delivery. Bioceram Dev Appl 8: 107. doi: 10.4172/2090-5025.1000107

Page 5 of 6

\begin{tabular}{|c|c|c|c|c|c|}
\hline Sample & Aspect ratio & Elongation & Roundness & Irregularity & Equivalent circle diameter $(\mu \mathrm{m})$ \\
\hline CCR & 0.53 & 0.47 & 0.82 & 3.04 & 9.07 \\
\hline $\mathrm{CCW}$ & 0.56 & 0.49 & 0.85 & 3.11 & 9.00 \\
\hline P-CCR $(10-90) \%$ & 0.41 & 0.59 & 0.64 & 2.32 & 11.45 \\
\hline P-CCRL (10-75-15)\% & 0.29 & 0.71 & 0.22 & 2.48 & 11.65 \\
\hline P-CCRL (10-65-25)\% & 0.22 & 0.78 & 0.31 & 2.90 & 13.27 \\
\hline P-CCRL (10-55-35)\% & 0.23 & 0.77 & 0.33 & 2.67 & 15.32 \\
\hline P-CCRL (10-45-45)\% & 0.21 & 0.79 & 0.25 & 2.76 & 15.29 \\
\hline P-CCRL (10-35-55)\% & 0.19 & 0.81 & 0.21 & 2.29 & 16.11 \\
\hline P-CCW (10-90)\% & 0.44 & 0.56 & 0.68 & 2.94 & 10.19 \\
\hline P-CCWL (10-75-15)\% & 0.33 & 0.67 & 0.37 & 2.64 & 10.32 \\
\hline P-CCWL (10-65-25)\% & 0.35 & 0.65 & 0.31 & 2.61 & 11.24 \\
\hline P-CCWL (10-55-35)\% & 0.36 & 0.64 & 0.34 & 2.72 & 13.01 \\
\hline P-CCWL (10-45-45)\% & 0.32 & 0.68 & 0.38 & 2.28 & 12.67 \\
\hline P-CCWL (10-35-55)\% & 0.29 & 0.71 & 0.25 & 2.33 & 13.32 \\
\hline
\end{tabular}

Table 3: Morphological parameters of the biopolymer extracts and piroxicam powder samples.

their high percentage porosity, hence the observed delivery rate (Figures 3-6). In the piroxicam formulations, P-CCRL (10-35-55\%) has the highest particle size. The larger the particles size, the lower the percentage porosity of the formulated powder and the lower the rate of release of the active ingredient.

\section{Conclusion}

The FTIR spectra indicated that the biopolymer extracts were chitosan and that there was no interaction between piroxicam and the biopolymer extracts. The inclusion of lactose in the piroxicam formulation resulted in tablets with low porosity because the lactose served as filler, which fills the pores of the piroxicam tablets during compression and thus enhanced the sustain release of piroxicam; however, the release rate has been found to also depend on time, compression pressure and the percentage of lactose and chitosan used in the formulation.

\section{References}

1. Adeoye O, Alebiowu G (2013) Flow, packing and compaction properties of novel co-processed multifunctional directly compressible excipients prepared from tapioca starch and mannitol. Pharm Dev Technol 23: 97-98.

2. Agnihotri SA, Mallikarjuna NN, Aminabhavi TM (2004) Recent advances on chitosan-based micro- and nanoparticles in drug delivery. J Control Release 100: 5-28.

3. Alebiowu G, Itiola OA (2003) Effects of starches on the mechanical properties of paracetamol tablet formulations. II. Sorghum and plantain starches as disintegrants. Acta Pharm 53: 1-8.

4. Alebiowu G, Itiola OA (2002) Compressional characteristics of native and pre-gelatinized forms of sorghum, plantain, and corn starches and the mechanical properties of their tablets. Drug Dev Ind Pharm 28: 663-672.

5. Almeida-Prieto S, Blanco-Mendez J, Otero-Espinar FJ (2007) Microscopic image analysis techniques for morphological characterization of pharmaceutica particles: Influence of software and the factor algorithms used in the shape factor estimation. Eur J Pharm Biopharm 67: 766-776

6. Al-Sagheer FA, Al-Sughayer MA, Muslim S, Elsabee MZ (2009) Extraction and characterization of chitin and chitosan from marine sources in Arabian Gulf. Carbohydr Polym 77: 410-419.

7. Amidon GE, Secreast PJ, Mudie D (2009) Particle, powder, and compact characterization. In: Developing solid oral dosage forms: pharmaceutical theory and practice. Qiu Y, Chen Y, Zhang GGZ (eds), New York: Elsevier Inc. pp: 163-186.

8. Bernkop-Schnürch A, Dünnhaupt S (2012) Chitosan-based drug delivery systems. Eur J Pharm Biopharm 81: 463-469.

9. Bodhmage A (2006) Correlation between physical properties and flowability indicators for fine powders. M.Sc. Thesis, Saskatchewan University, Canada. pp: 112-113.
10. Boretos JW, Eden M (1984) Contemporary biomaterials: Material and host response, clinical applications, new technology and legal aspects. Noyes Publications, Park Ridge, New Jersey, USA. p: 673.

11. Garcia-Fuentes M, Alonso MJ (2012) Chitosan-based drug nano-carriers: Where do we stand? J Control Release 161: 496-504.

12. Lemons JE, Ratner BD, Hoffman AS, Schoen FJ (2013) Biomaterials science an introduction to materials in medicine (3rd edn). Elsevier Ltd, Amsterdam The Netherlands.

13. Li Q, Dunn ET, Grandmaison EW, Goosen MFA (1992) Applications and properties of chitosan. J Bioact Compat Polym 7: 370-397.

14. Martindale-Extra Pharmacopoeia (1982) The pharmaceutical preparations. London. p: 276.

15. Media Cybernetics (2002). Image-pro plus - Application notes. Silver Spring: Media Cybernetics.

16. Michrafy A, Ringenbacher D, Tchoreloff $P$ (2002) Modelling and compaction behavior of powders: application to pharmaceutical powders. Adv Powder Technol 127: 257-266

17. Mohammed MH, Williams PA, Tverezovskaya O (2013) Extraction of chitin from prawn shells and conversion to low molecular mass chitosan. Food Hydrocoll 31: 166-171.

18. Negrea P, Caunii A, Sarac I, Butnariu M (2015) The study of infrared spectrum of chitin and chitosan extract as potential sources of biomass. Dig J Nanomater Biostruct 10: 1129-1138.

19. Ogunjimi AT, Alebiowu G (2013) Material and tableting properties of Azadirachta indica gum. Acta Pol Pharm 71: 107-118.

20. Park JH, Saravanakumar G, Kim K, Kwon IC (2010) Targeted delivery of low molecular drugs using chitosan and its derivatives. Adv Drug Deliv Rev 62 $28-41$

21. Pawlak A, Mucha M (2003) Thermogravimetric and FTIR studies of chitosan blends. Thermochimica Acta, 396: 153-166.

22. Pillay V, Fassihi R (2000) A novel approach for constant rate delivery of highly soluble bioactives from a simple monolithic system. J Control Release 16: 67-78.

23. Puvvada YS, Vankayalapati S, Sukhavasi S (2012) Extraction of chitin from chitosan exoskeleton of shrimp for application in the pharmaceutical industry. ICPJ 1: 258-263.

24. Ramya R, Sudha PN, Mahalakshmi J (2012) Preparation and characterization of chitosan binary blend. IJSRP 2: 1-9.

25. Ravi KN, Palanichamy S, Rajesh M, Godwin T, Rajadhas AV, et al. (2010) Formulation and evaluation of orodispersible piroxicam tablets. J Pharm Sci \& Res 2: 615-621.

26. Rinaki E, Valsami G, Macheras P (2003) The power law can describe the "entire" drug release curve from HPMC-based matrix tablets: a hypothesis. Int J Pharm 255: 199-207.

27. Rinaudo M (2012) Chitin and chitosan: Properties and applications. Prog Polym Sci 31: 603-632 
Citation: Akinwole IE, Oyatogun GM, Adenigba AE, Ayodele TJ, Oluwasegun KM, et al. (2018) Synthesis and Characterization of Cowry and Crab Shells Based Chitosan for Drug Delivery. Bioceram Dev Appl 8: 107. doi: 10.4172/2090-5025.1000107

Page 6 of 6

28. Riva R, Ragelle H, Rieux A, Duhem N, Je'rome C et al. (2011) Chitosan and chitosan derivatives in drug delivery and tissue engineering, Adv Polym Sci 244: 19-44.

29. Saikia C, Gogoi P, Maji TK (2015) Chitosan: A promising biopolymer in drug delivery applications. J Mol Genet Med S4: 006.

30. Satoskar RS, Bhandarkar SD (2001) Pharmacology and pharmacotherapeutics. Popular Prakasan Pvt. Ltd, Mumbai. p: 173.

31. Sonia TA, Sharma CP (2011) Chitosan and its derivatives for drug delivery perspective. Adv Polym Sci 243: 23-54.

32. Tomihata K, Ikada Y (1997) In-vitro and In-vivo degradation of films of chitin and its deacetylated derivatives. Biomaterials 18: 567-575.

33. Varshosaz $\mathrm{J}$ (2007) The promise of chitosan microspheres in drug delivery systems. Expert Opin Drug Deliv 4: 263-273.

34. Vikesh S, Rajashree MS, Bolmal UB, Manvi FV (2007) Formulation and evaluation of piroxicam dispersible tablets using natural disintegrants. The Indian Pharmacist 6: 685-688.

35. Werle M, Bernkop-Schnürch A (2008) Hiolated chitosans: Useful excipients for oral drug delivery. J Pharm Pharmacol 60: 343-348.

36. Williams DF (1987) Definitions in Biomaterials, Proceedings of Consensus Conference of the European Society for Biomaterials, Chester, England, March 3-5 1986, Vol.4, Elsevier, New York, USA.

37. Wojnar L (1999) Image analysis. CRL Press, Washington, D.C., USA.

38. Younes $Y$, Rinaudo M (2015) Chitin and chitosan preparation from marine sources. Structure, properties and applications. Mar Drugs 13: 1133-1174. 